\title{
MÍDIA E BIOÉTICA: REPENSANDO A ÉTICA NA INFORMAÇÃO
}

\author{
Celso Moreira de Mattos \\ Faculdade Metropolitana/IESB, Londrina e Faculdade Maringá, Maringá, Paraná, Brasil. \\ celsomattos@sercomtel.com.br
}

\section{José Eduardo de Siqueira}

Universidade Estadual de Londrina, Paraná, Brasil.

jtsique@sercomtel.com.br

\begin{abstract}
Resumo: Estamos vivendo um novo paradigma comunicacional. A informação é produzida de forma instantânea, aumentando o risco do rompimento dos valores éticos que devem reger os profissionais da informação. Este estudo parte de uma explanação geral sobre ética na imprensa e sua correlação com a bioética e a filosofia. Atualmente, os profissionais da informação estão mais vulneráveis do que nunca, pois precisam trabalhar com temas complexos e globalizados que exigem tomadas de decisões reflexivas. Mas será que estão preparados eticamente para gerar práticas jornalísticas responsáveis? Para responder a essa pergunta, realizamos uma pesquisa com 100 jornalistas graduados em sete diferentes universidades brasileiras. O objetivo foi avaliar o que pensam sobre a importância das reflexões éticas, o conhecimento que possuem sobre o tema e se a formação acadêmica que tiveram foi suficiente para o exercício ético da profissão. A pesquisa revelou que o despreparo ético dos profissionais passa pela formação acadêmica, que não tem dado o devido valor a este aspecto da profissão.
\end{abstract}

Palavras-chave: Imprensa. Ética. Bioética. Filosofia. Jornalismo.

\begin{abstract}
We are experiencing a new communicational paradigm. Information is produced in an instantaneous way increasing the risk of breaking ethical values, which should rule over the information professionals. This present study is part of a general explanation about ethics in the press and its correlation with bioethics and philosophy. Today, more than ever, are information professionals vulnerable, as they need to work with complex and globalized themes that require reflective decision making. Nevertheless, are ethically prepared to generate journalistically responsible practices? To answer such a question, we carried out a research involving 100 journalists graduated from seven different Brazilian universities. The objective was to evaluate what they think about the importance of ethical reflections, how much they know about this theme and whether their academic background was enough for the ethical practice of their profession. The research evidenced that the lack of ethical preparation of those professionals is overlooked, by their academic formation, which has not given proper relevance to such an aspect of the profession.
\end{abstract}

Key words: Press. Ethics. Bioethics. Philosophy. Journalism. 
No início dos anos 1960, quando o sociólogo canadense Marshall McLuhan decretou que os meios de comunicação de massa haviam reduzido o mundo à dimensão de uma "aldeia global", sua afirmação foi considerada revolucionária, quase profética. Na época, ainda não havia a proliferação dos canais de televisão a cabo, a informática estava apenas engatinhando e a palavra internet não existia. Entretanto, as revoluções tecnológicas das últimas quatro décadas provaram que, em parte, McLuhan estava certo: o mundo vive hoje uma comunicação planetária, exigindo dos profissionais da imprensa uma responsabilidade que vai muito além dos normativos e limitados códigos deontológicos.

Como observa Cornou, o trabalho dos jornalistas enfrenta, atualmente, muitas dificuldades porque esses profissionais estão mais sujeitos a pressões tradicionais dos poderes e do dinheiro, mas também à pressão cada vez mais constrangedora da velocidade, cuja expressão última é a informação em tempo real (CORNOU,1994).

Entretanto, o mais preocupante é que em tempos de intercâmbio planetário nos quais a informação se tornou instantânea, sendo transmitida para um número cada vez maior de pessoas, aumentou significativamente o risco do rompimento dos valores éticos que devem reger os profissionais da imprensa. Em contrapartida, ao mesmo tempo em que essas novas técnicas fortaleceram o poder da informação e a responsabilidade do jornalista perante a sociedade, aumentou seu grau de fragilidade. Hoje, esses profissionais estão mais sujeitos à vulnerabilidade do que nunca, pois precisam lidar com temas complexos e globalizados que exigem tomada de decisão reflexiva. Diante dessa realidade, é preciso questionar se os profissionais da informação estão preparados eticamente para gerar práticas jornalísticas responsáveis.

Para responder essa questão e propor alternativas de mudança de conduta, optamos por realizar pesquisa quantitativa, entrevistando por meio de questionário 100 jornalistas que atuam na imprensa escrita (jornais) e falada (rádio e televisão) na cidade de Londrina, Estado do Paraná, graduados em sete diferentes universidades. O objetivo foi avaliar o que pensam sobre a importância das reflexões éticas, o conhecimento que possuem sobre o tema e se a formação acadêmica que tiveram foi suficiente para que possam fazer o exercício ético no dia-a-dia. O resultado da pesquisa e sua análise serão apresentados na segunda parte deste trabalho, mas antes é preciso esclarecer o porquê da bioética estar aqui inserida e fundamentar a importância da ética na informação. 


\section{Resgate Histórico e Múltiplas Abordagens}

A palavra bioética foi utilizada pela primeira vez, em 1970, por Van Rensselaer Potter, que definiu bioética como uma ponte para o futuro, uma ética necessária para a reflexão sobre a vida no planeta. Essa definição, bastante abrangente, foi em 1988 batizada pelo próprio Potter de "Bioética Global" (POTTER, 1971; POTTER, 1988).

Desde sua concepção, há três décadas, foram agregadas à bioética novas definições que a transformaram em um campo de estudo interdisciplinar. A bioética é a articulação, a integração e o consenso de várias disciplinas, não só da área da saúde, mas também de outras áreas, como: antropologia, biologia, sociologia, psicologia, economia, direito, política, ecologia, filosofia, teologia etc. Envolve profissionais de saúde e todos aqueles que, com competência e responsabilidade, dispõem-se a refletir eticamente sobre a melhor conduta a ser prestada à pessoa humana (CORREIA, 1996).

Esse caráter pluralista da bioética é reforçado por outros autores ao preconizar que esse campo do saber trata da vida da natureza, da flora, da fauna e da vida humana, à luz dos valores humanos aceitos em uma sociedade democrática, pluralista, secular e conflitiva (PESSINI \& BACHIFONTAINE, 1991). Dessa forma, pode-se dizer que a bioética é uma proposta de diálogo não só na esfera individual, mas, principalmente, no campo coletivo. É acima de tudo uma área de estudo preocupada em propor uma reflexão sobre o novo e quais serão suas conseqüências para a humanidade.

Com base nesses conceitos, pode-se afirmar que a bioética já extrapolou a área médica e, hoje, deve ser compreendida como um campo de estudo pertinente a todos os profissionais, inclusive os jornalistas que, como intérpretes da realidade, devem estar em sintonia com os problemas contemporâneos e saber refletir sobre eles. Para isso, a imprensa precisa ser ética, autônoma e reflexiva. É necessário que os empresários da comunicação assumam uma posição menos mercantilista, atuando como "cães de guarda" do cidadão e não do poder estabelecido, como freqüentemente vem acontecendo. Por outro lado, os profissionais da informação precisam sair de sua confortável posição de "menoridade" e fazer uso da palavra - seu instrumento de trabalho - com mais criticidade e com uma visão de mundo menos míope e mais holística. Como propõe Capra, há uma crise de percepção e os problemas da nossa época não podem ser entendidos isoladamente (CAPRA, 1996). Para o autor, são problemas sistêmicos, ou seja, estão interligados e são interdependentes. Há soluções para os principais problemas, mas estas exigem mudança radical de 
paradigma. E esse reconhecimento ainda não atingiu as corporações, os profissionais e nem os professores das nossas maiores universidades.

Para Capra, o velho paradigma está alicerçado nos valores antropocêntricos, nos quais o ser humano é a centralidade; o novo paradigma, que ele chama de ecologia profunda, se baseia nos valores ecocêntricos, centralizados na Terra. É uma visão de mundo que reconhece o valor inerente da vida nãohumana. E quando essa concepção torna-se parte de nossa consciência cotidiana, surge um sistema ético radicalmente novo. Nessa linha de raciocínio, cabe discutir a responsabilidade moral dos cientistas e também dos profissionais da informação.

Em tempo de questões polêmicas como clonagem humana, terapia gênica, seqüenciamento genético, transplantes de órgãos, pesquisa com seres humanos, abortamento eugênico, transexualidade, alimentos geneticamente modificados, entre tantos outras que a tecnociência está trazendo à tona nesse início de século, os jornalistas, como transmissores de informação e formadores de opinião, não podem ficar à margem da discussão. Precisam participar dela como agentes ativos, pois, caso contrário, correm o risco de pecar por omissão.

É ingênuo pensar que será possível informar corretamente o leitor sobre questões tão polêmicas, usando apenas a relevante, mas insuficiente, ética do bom senso e os limitados códigos deontológicos. A reflexão sobre um conflito moral no exercício da profissão, realizada apenas sob o referencial do código deontológico, será, provavelmente, uma visão míope e muito restrita da problemática ética nele contida (KIPPER \& CLOTET, 1998).

Neste sentido, a bioética tem muito a contribuir com a imprensa, pois busca no passado e no presente uma reflexão transdisciplinar que vai muito além da ética normativa. É uma ética de compreensão planetária e que resgata a visão global do homem. A imprensa, assim como a área da saúde, está vivendo um novo paradigma frente aos avanços tecnológicos. Se no campo da medicina, a tecnologia tem interferido sensivelmente na relação médico-paciente, na comunicação não é muito diferente. Como defende Blázquez: a comunicação e a informação estão quase sempre em função da tecnologia e às custas da informação propriamente dita (BLÁZQUEZ,1994). É assim que surge o problema ético fundamental do conflito tecnologia-humanismo. As relações humanas diretas são substituídas pelo meio técnico, que se torna mais importante do que a dimensão humana, deixando em segundo plano a qualidade das mensagens.

Portanto, pensar a bioética para repensar a ética na imprensa não é uma proposta fora de contexto; é uma alternativa contemporânea que propõe um novo olhar sobre a ética na informação. Mas isso exige também repensar a 
formação e a atuação dos profissionais da informação. É impraticável pensar que será possível abordar temas tão polêmicos como descartes de embriões, eutanásia, alocação de recursos na saúde, clonagem humana ou terapêutica, terapia gênica e esterilização de doentes portadores de anomalias graves, fazendo um jornalismo de reprodução de idéias ou tendo como base uma ética apenas normativa. É preciso beber em fontes mais seguras e profundas. Esse alerta deve começar nos cursos de comunicação social, que precisam se preocupar em formar jornalistas mais preparados para o exercício da profissão num mundo globalizado e pulverizado de problemas complexos, como os citados.

Se o código de ética profissional é insuficiente para exercício pleno da profissão, é preciso buscar respaldo nos fundamentos filosóficos da ética jornalística como recomenda Bucci ao argumentar que a ética jornalística é um sistema com lógica própria (BUCCI, 2000). Não é um receituário; é antes um modo de pensar que, aplicado ao jornalismo, dá forma aos impasses que requerem decisões individuais e sugere equações para resolvê-los. O que se deve ter em conta, de início, é que a prática do jornalista não é auto-suficiente em sua dimensão ética, mas vai buscar em correntes filosóficas que trataram da ética em geral os parâmetros para enfrentar seus dilemas cotidianos.

Como a prática jornalística trabalha com direitos e obrigações, a ética normativa não pode ser descartada, mas interpretada sob um ponto de vista mais abrangente, que vai além da normatização dos códigos profissionais. Não se pode esquecer que a ética kantiana é normativa, pois se sustenta na esfera do dever e da obrigação e, por isso, tem uma grande importância para o exercício do profissional da informação. O imperativo categórico de Kant deixa isso bem claro: "Age de tal modo que a máxima da tua vontade possa valer sempre ao mesmo tempo como princípio de uma legislação universal" (KANT, 1985). Com esta formulação, o filósofo proporciona, na prática, um critério para o agir moral. Se queres agir moralmente, age de forma que tuas ações possam realmente ser universalizáveis. Portanto, dizer a verdade e ser justo fazem parte do imperativo kantiano, o qual condiz perfeitamente com a prática jornalística. Como sintetiza Rossi, a melhor preparação jornalística será certamente jogada no lixo se não for acompanhada de rigorosa honestidade no trabalho (ROSSI, 1980). E aí, o conceito de honestidade deve ser entendido no seu sentido mais amplo.

Como estamos diante de grandes transformações sociais e tecnológicas, impensáveis na época de Kant, vale a pena acrescentar um outro imperativo menos normativo e mais abrangente, formulado pelo pensador contemporâneo Hans Jonas, que tem muito a contribuir para uma imprensa mais responsável 
e ética: "Age de tal maneira que os efeitos de tua ação sejam compatíveis com a permanência de uma vida humana autêntica e não ponhas em perigo a continuidade indefinida da humanidade na Terra" (JONAS apud SIQUEIRA, 1998).

O que Jonas propõe é que precisamos ser conscientes e responsáveis para que nossas ações não coloquem em risco a vida alheia, um imperativo que se enquadra muito bem no trabalho do profissional da informação. A imprensa tem uma grande carga de responsabilidade e poder; o exercício destas prerrogativas deve ser rigorosamente pensado para que não se cometam erros como, por exemplo, o da Escola Base, ocorrido em abril de 1994, no bairro da Aclimação em São Paulo. A genealogia de erros cometidos pela imprensa é esclarecida no livro-reportagem Caso Escola Base - Os Abusos da Imprensa, que disseca um dos mais perversos acontecimentos já promovidos pelo jornalismo no Brasil (RIBEIRO, 2001).

\section{Em Busca do Esclarecimento}

O imperativo categórico não é a única contribuição que Kant traz para se fazer uma imprensa mais justa e autônoma. Sua tese Resposta à pergunta: que é esclarecimento?", de 1783, pode ser interpretada à luz de uma imprensa com voz própria e não de submissão, como vem sendo praticado por muitos meios de comunicação. Kant usa o termo "esclarecimento" para determinar o momento em que o homem sai do estado de menoridade, no qual se mantém por própria culpa, por não ter coragem de assumir seu próprio conhecimento. O primeiro passo para atingir o esclarecimento, a maioridade, é se desfazer dos tutores que, por sua própria comodidade, o mantém distante das luzes do saber.

Se num passado recente a imprensa era impossibilitada de exercer sua maioridade, porque sua liberdade era cassada pelo regime militar, hoje, sua dependência do poder econômico público e privado a mantém na condição de menoridade, sem liberdade para fazer uso público da razão, como afirma Kant: "O uso público de sua razão deve ser sempre livre e só ele pode realizar o esclarecimento" (KANT, Op. cit.); Por outro lado, o jornalista constantemente ameaçado pelo fantasma do desemprego, precisando trabalhar em mais de um local para se manter e, em muitos casos, sem tempo, condições financeiras e disposição própria para se aperfeiçoar profissionalmente, também se mantém num estado de menoridade. Quem sai perdendo com isso é o leitor que fica à mercê de uma imprensa enfraquecida, pobre, fragmentada 
e que nem sempre diz a verdade. Como defende Kucinski não há diferença entre um médico que mata e um jornalista que mente (KUCINSKI, 2000).

Se a imprensa não cumpre com precisão seu papel de esclarecer com fidedignidade e profundidade o leitor, não está contribuindo para formar um cidadão emancipado e capacitado para exercer a maioridade que faz uso próprio da razão. Isso equivale violar o direito sagrado do cidadão que é o de ser informado com veracidade. Portanto, o jornalista não pode compactuar com isso, caso contrário não estará cumprindo com sua função. Como preconiza Bucci, a razão de ser do repórter, de um editor ou de um repórter fotográfico não é a da empresa que lhe paga o salário, mas a existência do direito à informação, o qual pertence ao cidadão. Este é o destinatário do trabalho jornalístico, que no final é quem paga a conta: é quem compra o jornal ou a revista e quem os anunciantes querem conquistar quando investem altas somas em publicidade.

\section{Por uma Ética de Responsabilidade}

De acordo com ética da responsabilidade de Weber, o homem age com vistas às conseqüências de seus atos, assumindo a responsabilidade pelo que faz e também pelo efeito de suas ações (WEBER, 1987). Apesar de lembrar a ética utilitarista, que defende que "a melhor ação é aquela que produz a maior felicidade ao maior número de pessoas", as duas não podem ser confundidas. Max Weber, filósofo do século XX, nunca se identificou com o utilitarismo.

O utilitarismo é uma fonte importante da ética jornalística, mas também muito criticada como aponta Bucci. A fraqueza dessa filosofia aplicada ao jornalismo é grave: como pode um mero profissional da imprensa prever com eficácia as conseqüências de seus atos? Jornalistas não são profetas. Uma ética que depende, então, de cálculos que levam em sua receita uma boa dose de futurologia, tem seus limite.

Para Weber, que ocasionalmente foi jornalista, a responsabilidade do profissional da imprensa é, antes de tudo, para com o público, pelo direito deste de ser informado. Weber defende essa idéia quando diz: "Raramente suspeitamos que a responsabilidade do jornalista é muito maior que a do cientista e que o sentimento de responsabilidade de todo jornalista honrado em nada é inferior ao de qualquer outro intelectual" (WEBER, apud CORNU, 1994). Com isso, Weber lembra que tanto o profissional da informação quanto o da ciência devem se inspirar na modéstia. 
É em nome dessa responsabilidade que o jornalista deve pautar sua conduta no dia-a-dia, mesmo tendo que competir diariamente com a concorrência entre os veículos de informação e a difusão dos acontecimentos em tempo real, que contribuem cada vez mais para o precário trabalho de verificação dos fatos. Como observa Cornu, a informação planetária e satelizada transforma-se numa exposição permanente de fragmentos crus da realidade. A confirmação dos fatos e a crítica das fontes são comprometidas pela instantaneidade da comunicação. É contra a própria velocidade da informação moderna, contra a pressão do tempo, que o jornalista responsável deve lutar obstinadamente. Esta é a única maneira de preservar os laços entre sua atividade e a do investigador. Um laço que o jornalista deve defender para que nunca se rompa.

Na chamada era da informação, muitos entusiastas celebram o advento da nova mídia como o "nirvana da liberdade e prosperidade". Essa euforia é perigosa, já que os efeitos do novo padrão de mídia são ainda imprevisíveis a longo prazo. Há que se ressaltar ainda o papel central desempenhado pelas mídias clássicas nos últimos tempos, ao atingir uma audiência de massa. Para Dizard ela serviu não só como provedora de informações, mas também como uma espécie de fator de união nacional que liga as pessoas segundo interesses compartilhados (DIZARD JR., 2000).

Um outro problema, aponta Dizard, é saber se as novas tecnologias vão aumentar, em todo o mundo, a desigualdade entre os chamados "ricos e pobres em informação". Levantamentos apontaram que o público que tem fácil acesso à informação leva vantagem, por exemplo, no progresso pessoal e profissional. A nova elite, formada pelos detentores da informação, pode isolar-se do restante da sociedade. É importante questionar se a nova mídia tornará a sociedade mais capacitada para lidar com as complexas questões de uma democracia pós-industrial ou contribuirá para aumentar o abismo entre ricos e pobres de informação. Para compreender essa nova mídia, os dilemas éticos precisam estar constantemente se transformando, assumindo complexidades inéditas, e não há receitas prontas para resolvê-los. Para enfrentar isso Bucci recomenda que os jornalistas tenham cada vez mais familiaridade com essas e outras correntes filosóficas aplicadas ao seu ofício e com os paradigmas que elas oferecem, pois dependem disso para estar à altura de sua profissão e dos desafios que ela encerra.

Foi partindo desta premissa que decidimos realizar uma pesquisa com 100 jornalistas que atuam na imprensa na cidade de Londrina, Estado do Paraná, para verificar qual a familiaridade que têm com as correntes filosóficas da 
ética, fundamentais para o exercício responsável e ético da profissão em tempos de intercâmbio planetário, inovações tecnológicas e avanços científicos.

\section{Sistemática e Aplicação da Pesquisa}

As entrevistas com os sujeitos da pesquisa foram feitas por meio de um questionário composto de cinco perguntas abertas. Para dar maior liberdade de expressão aos profissionais, eles não precisaram se identificar, apenas informar a Universidade na qual se formaram, o ano de graduação e o cargo que ocupavam no momento da entrevista. Todos responderam o questionário no local de trabalho, não sendo permitido que o mesmo fosse levado para ser preenchido em casa, o que poderia oportunizar uma pesquisa bibliográfica prévia antes de responder às perguntas e mascarar o resultado do estudo.

Foram entrevistados no período de 20 de agosto a 20 de setembro de 2001, jornalistas graduados em Comunicação Social, habilitação em Jornalismo, que atuam na imprensa escrita (jornais), falada (televisão e rádio) e em assessorias de imprensa. Os jornalistas provisionados (aqueles que começaram a trabalhar na profissão antes da criação dos cursos de Comunicação Social, na década de 70), não foram entrevistados, pois são formados, em sua maioria, nos cursos de Direito, Letras e Ciências Sociais. O objetivo desta pesquisa quantitativa foi o de fazer um diagnóstico do conhecimento ético-filosófico desses profissionais. O questionário perguntou o seguinte:

1. Se julgavam as reflexões ético-filosóficas importantes para o exercício da profissão; 2. Considerando que filósofos como Platão, Aristóteles, Tomás de Aquino, Hume, Locke, Kant, Spinoza, Weber e Habermas foram grandes formuladores da ética, o que já haviam lido sobre eles; 3. Que citassem pelo menos o pensamento central de um desses filósofos; 4. O que sabiam sobre John Rawls e sua teoria; 5. Se consideravam que o conteúdo ético-filosófico dado no curso de Comunicação Social-habilitação em Jornalismo havia sido suficiente para que pudessem fazer reflexões éticas no dia-a-dia da profissão?

\section{Perfil dos Entrevistados}

Os 100 jornalistas pesquisados se graduaram no período de 1976 a 2000, sendo 5 (5\%) na década de 1970; 35 (35\%) na de 1980; 56 (56\%) na de 1990 e 4 (4\%) em 2000. Deste total 79 (79\%) se formaram na Universidade Estadual 
de Londrina (UEL), 7 (7\%) na Universidade Federal do Paraná (UFPR), 5 (5\%) na Universidade Estadual de Ponta Grossa (UEPG), 4 (4\%) na Pontifícia Universidade Católica do Paraná (PUC-PR), 2 (2\%) na Universidade Estadual Paulista, de Bauru-SP (Unesp), 1 (1\%) na Universidade de Brasília (UnB), 1 (1\%) na Fundação Cásper Líbero, de São Paulo e 1 (1\%) na Universidade do Oeste Paulista (Unoeste), de Presidente Prudente.

No que diz respeito aos cargos, 56 (56\%) eram repórteres, 23 (23\%) editores, 9 (9\%) assessores de imprensa, 8 (8\%) pauteiros e 4 (4\%) redatores. O resultado da pesquisa revelou que $94 \%$ dos jornalistas acham que as reflexões ético-filosóficas são importantes para o exercício da profissão. Dos 100 entrevistados, apenas 6 (6\%) não compactuam da mesma opinião, afirmando que o mais importante é se pautar pelo código de ética, como fica exemplificado nesta declaração: "Na minha opinião as reflexões ético-filosóficas não são importantes. O jornalista precisa seguir seu código de ética como qualquer outro profissional" (assessor de imprensa, formado pela UFPR em 1991).

Em contrapartida, a pesquisa revelou opinião oposta e bastante contundente: "As reflexões ético-filosóficas são importantes porque o jornalista é antes de tudo um formador de opinião e deve buscar o conhecimento da ética filosófica para o exercício mais responsável e engajado da profissão" (editora, formada pela UnB em 1982). No entanto, apesar de $94 \%$ defenderem posição semelhante, a pesquisa mostrou que o conhecimento dos fundamentos filosóficos da ética passa longe das redações, como veremos a seguir.

Entre os filósofos que foram grandes formuladores da ética, Platão é o mais conhecido. Dos 100 entrevistados, Platão foi citado por 44 (44\%), seguido de Weber (29\%); Aristóteles (25\%); Kant (16\%); Tomás de Aquino (13\%); Habermas (6\%); Spinoza (5\%); Locke (4\%) e Hume (0\%). Além disso, 36\% afirmaram que não tiveram nenhum contato com a obra desses filósofos. Ainda sobre essa questão, apenas $14 \%$ souberam citar o nome de pelo menos uma obra dos filósofos mencionados, os outros $86 \%$ disseram não se recordar do título dos livros ou dos textos que leram. Entretanto, o que mais chamou a atenção na pesquisa, foi o fato de Habermas, o último grande pensador da Escola de Frankfurt, que escreveu, entre outras obras, a Teoria da Ação Comunicativa, publicada em 1981, ter sido mencionado em apenas $6 \%$ das respostas. Sua obra é de grande interesse para o estudo da Teoria da Comunicação, disciplina que faz parte do currículo do curso de Jornalismo. Dizer que a obra de Habermas é muito contemporânea, não justifica tal desconhecimento, pois 56\% dos entrevistados se formaram na década de 1990. 
Isso mostra que desse total, apenas 10,7\% responderam conhecer a obra de Habermas, o que continua sendo uma porcentagem muito baixa. Estudar Habermas no curso de Comunicação Social é tão importante quanto estudar Walter Benjamin, Theodor Adorno e Herbert Marcuse, também pensadores da Teoria Crítica.

Apenas 22\% dos jornalistas souberam responder corretamente, porém de forma bastante superficial, qual é o pensamento central de pelo menos um dos filósofos acima citados. Os outros 78\% preferiram não arriscar porque não tinham certeza. Sobre quem é o filósofo John Rawls, 98\% responderam nunca ter ouvido falar do pensador norte-americano, somente $2 \%$ se referiu a Rawls como o autor de uma Teoria da Justiça. Por seu tratado, podemos atribuir a John Rawls a revitalização dos campos da filosofia política e da ética. Seus estudos trazem de volta a idéia do contrato social e dão continuidade ao imperativo categórico de Kant, além de propor uma alternativa ao utilitarismo, método predominante na ética durante a maior parte do século XX.

Dada a importância deste pensador contemporâneo, cuja obra faz uma profunda abordagem sobre justiça, liberdade, direito e desigualdades sociais, sua ausência no currículo dos cursos de jornalismo é uma questão a ser repensada, pois o trabalho de Rawls abre espaço para novas reflexões sobre a forma de pensar a sociedade. Os profissionais da informação do século XXI não podem desconhecer sua teoria.

Mas esta não é a única falha na formação do jornalista, como pode ser observado nas respostas dadas pelos entrevistados na pergunta cinco: 92\% disseram que o conteúdo ético-filosófico dado no curso de Comunicação Social é insuficiente para que o jornalista possa fazer reflexões éticas no exercício da profissão, com exemplifica esta declaração:

"O conteúdo ético-filosófico no curso foi aplicado de forma diluída e fragmentada. Na disciplina de Ética e Legislação em Jornalismo, por exemplo, o conteúdo restringia-se à leitura e análise do código de ética. Já na disciplina de Filosofia, aplicada no $1^{\circ}$ ano do curso, as teorias foram passadas como se o objetivo fosse apenas o de cumprir o programa. $\mathrm{O}$ aproveitamento do aluno era praticamente nulo" (repórter, formado pela UEL em 1993).

Apenas 8\% consideraram o conteúdo suficiente ou razoável, como pode ser observado na resposta a seguir: 
"O curso oferece algumas oportunidades de formação humanística, até com razoável conteúdo ético-filosófico. O problema maior parece ser os estudantes que não chegam à universidade preparados o suficiente para aprofundar discussões sobre ética e filosofia" (editor, formado pela UEL em 1985).

Como fica evidenciado nesses resultados, os jornalistas que estão atuando na profissão consideram as reflexões ético-filosóficas importantes, mas se sentem desprovidos dessa fundamentação, o que pode repercutir na qualidade do jornalismo por eles praticado numa época em que a informação enfrenta desafios planetários. Como a pesquisa envolveu profissionais formados em diferentes instituições, o problema não reside apenas no curso de Comunicação Social da UEL, mas em todos aqueles pesquisados. Portanto, a formação do jornalista precisa ser repensada e readequada às exigências do mundo atual. Esse é o papel da universidade. Pensar a sociedade e não se preocupar apenas em colocar no mercado profissionais tecnicamente bem-preparados.

Sobre isso, a vale pena citar o argumento de Bucci:

"A universidade por mais que tenha em vista o mercado de trabalho, tem sua vocação mais funda no cultivo da reflexão. Sua melhor contribuição está em formar profissionais não tecnicamente prontos, mas críticos, capazes de pensar por si mesmos. A universidade é o celeiro da pesquisa e do questionamento intelectual (...). É aí que os jovens devem tomar contato com as correntes filosóficas [grifo nosso] pelas quais a ética pode ser estudada e aplicada" (BUCCI, Op. cit.).

A verdade é que a prática jornalística nunca precisou tanto de reflexão como no momento atual, devido à complexidade política, econômica e tecnológica em que estamos vivendo. Por isso,

"uma redação de jornal não é um balcão onde notícias são empacotadas.

(...) Jornalistas não são mineradores de informação exclusiva que ocasionalmente são instados a pensar, mas precisam ser pensadores com grande capacidade executiva. O jornalismo é uma atividade intelectual - ou é inconseqüente e tolo" (BUCCI, Op. cit.).

A exemplo da universidade, as redações também precisam funcionar como um celeiro encarregado de pensar. A qualidade do que os jornais apuram, 
escrevem, narram, editam e veiculam mostra como eles pensam (ou como não pensam) a sociedade. Para isso, as empresas jornalísticas precisam deixar de se fixar apenas em cifras e investir mais na qualificação dos seus profissionais, caso contrário vão continuar fazendo um jornalismo reducionista. Como preconiza Serva, este momento coloca uma oportunidade única de reposicionamento do jornalismo como um todo, com grande proveito para os jornais, que devem buscar, aprimorar sua estrutura analítica e histórica em substituição à vocação meramente noticiosa (SERVA, 2001).

Por outro lado, os jornalistas precisam investir mais em sua qualificação profissional. É chocante observar que a maioria não volta a estudar e nem a se reciclar depois de formados, quando vivemos uma época em que as mudanças sociais, comportamentais e tecnológicas acontecem em ritmo vertiginoso.

Blázquez aponta que alguns teóricos e profissionais da informação defendem com certa arrogância que a verdade é um assunto puramente subjetivo e egocêntrico, que os fatos ocorrem de acordo com a lente usada para olhá-los, o que não deixa de ser uma visão que muito lembra os sofistas gregos (BLÁZQUEZ, 1994). O autor compara esta afirmação dizendo que muitos destes teóricos e profissionais da comunicação contemporânea não são senão sobreviventes dos sofistas e embusteiros de todos os tempos, sob as ordens niilistas e irresponsáveis da mal denominada pós-modernidade. Para Blázquez, a ética não só exige o respeito ao público por parte dos jornalistas, mas explica a razão adequada pela qual o público deve ser respeitado:

"A ética jornalística continuará sendo ineficaz enquanto não se purificar da ética em vigor, desenvolvendo éticas parciais para as diversas modalidades de comunicação, meios, profissões e contextos" (BLÁZQUEZ, Op. cit.).

Apesar da crítica ser oportuna, não é aplicável a todos os profissionais da imprensa. Não podemos esquecer que existem muitos jornalistas que constróem suas carreiras tendo como base valores éticos, conduta responsável e preocupação com o social, como mostrou a pesquisa, na qual 94\% dos entrevistados se posicionaram favoravelmente às reflexões ético-filosóficas com relação ao exercício da profissão, o que é bastante louvável.

A responsabilidade global em matéria de informação, como coloca Cornu, responde às condições descritas por Hans Jonas, quando constata a dificuldade de pensar uma ética em um mundo onde, por causa do avanço tecnológico, o poder e as criações possíveis - nas quais deve ser incluído o 
poder da mídia. Na construção simbólica da realidade - respondem a modalidades inteiramente novas. Sobre isso, Cornu argumenta que a definição de uma ética global da mídia passa por uma conscientização comum e não exclusiva dos agentes da informação, dos responsáveis pela mídia, do público e dos Estados, objetivando definir o que poderia equivaler, em matéria de informação, a um "princípio de responsabilidade": uma responsabilidade geral e solidária que busca firmar, pela participação de cada personagem, a liberdade de comunicação como bem comum da sociedade.

Foi partindo desta premissa que destacamos desde o início deste trabalho, a importância de pensar a bioética para repensar a ética na imprensa, considerando que a bioética propõe, em linhas gerais, uma nova ética para a vida no planeta. Uma ética com a participação de todas as esferas da sociedade, tendo como objetivo maior a permanência de uma vida autenticamente humana na Terra, como defende Jonas. É impraticável, ingênuo e míope pensar uma ética na informação desvinculada de uma ética global, capaz de colocar o cidadão e seu direito à vida e à verdade acima dos interesses de mercado.

\section{Conclusão}

O objetivo deste trabalho foi de mostrar que professores do curso de jornalismo, profissionais e empresários da imprensa, precisam começar a discutir, a partir de novos paradigmas, as deficiências aqui apontadas. Essa discussão não passa por outro caminho a não ser o da educação. A formação do jornalista precisa ser repensada, revitalizada e horizontalizada. Entretanto, essa discussão não pode se restringir ao meio acadêmico; precisa ser debatida com os profissionais da imprensa, com as entidades representativas da categoria e com a sociedade. Esse debate aberto, à luz dos problemas atuais, é um serviço de utilidade pública, que educa o espírito crítico e ajuda a melhorar a imprensa.

A pesquisa refletiu apenas uma deficiência: o desconhecimento sobre os fundamentos da ética, requisito inexorável diante da complexidade do momento em que vivemos. No entanto, existem outras deficiências a serem constatadas e sanadas e este é o único caminho para se fazer um jornalismo de excelência, que contribua para a formação do cidadão; enfim, um jornalismo de responsabilidade social, comprometido com os interesses coletivos e em sintonia com seu tempo. 
Assim como na área da saúde, os desafios da imprensa neste novo século são grandes, exigindo tomadas de decisão firmes, éticas e reflexivas. E, para solucionar com êxito esses desafios atuais e futuros, precisamos encontrar novos modelos de pensamento, construir uma nova ética, uma nova escala de valores e novos conceitos de comportamento. Para esta mudança de paradigma, a bioética com seu pluralismo de idéias e sua transdisciplinariedade, pode ser uma grande aliada na construção de um jornalismo mais comprometido com a cidadania e menos reducionista. Por não se circunscrever a um campo delimitado, mas se interligar num plano superior com outras ciências, coloca um ponto final no relevante, mas ultrapassado método cartesiano de conhecimento.

Há que se abrir os horizontes na formação do jornalista, permitindo que o futuro profissional da informação tenha contato mais direto e profícuo com as correntes clássicas de pensamento, mas também para apresentar a ele pensadores contemporâneos como Adela Cortina, Gilbert Hottois, Hans Jonas, John Rawls, Volnei Garrafa, Léo Pessini e Márcio Fabri, que propõem novos modelos de agir eticamente frente às mudanças tecnológicas, que trazem em seu bojo a promessa de um mundo admirável, mas também estéril, frágil e desprovido de humanismo. Não é o caso de se criar novas disciplinas nos já exauridos currículos de Comunicação Social, mas de abrir a discussão para outros campos do saber, possibilitando que o aluno tenha contato com uma diversidade maior de idéias. Para atuar em um mercado globalizado, o profissional precisa ter uma formação que lhe permita transitar com mais familiaridade entre diferentes correntes de pensamento. Afinal, esse é o papel da universidade: promover e multiplicar conhecimento, formando cidadãos com capacidade de reflexão.

A academia não deve ser a única provedora e responsável para a boa qualificação do profissional, até porque ela não tem controle sobre aqueles que já se encontram no mercado de trabalho. Portanto, é papel das entidades representativas da categoria, no caso dos profissionais da imprensa, do Sindicato, da Associação Nacional dos Jornalistas (ANJ) e da Federação Nacional dos Jornalistas (FENAJ), investir em fóruns de discussão sobre ética nos meios de comunicação.

Por outro lado, as empresas jornalísticas precisam ser menos mercantilistas e investir mais na qualificação do profissional, pois quem ganhará com isso será o cidadão, a quem o jornalismo deve prestar contas. Caso contrário, se continuará produzindo uma imprensa meramente noticiosa que em nada contribui para a formação do ser humano. 


\section{Referências bibliográficas}

BLÁZQUEZ, N. Ética e meios de comunicação. São Paulo, Paulinas, 1994.

BUCCI, E. Sobre ética e imprensa. São Paulo, Companhia das Letras, 2000.

CAPRA, F. A teia da vida: uma nova compreensão científica dos sistemas vivos. São Paulo, Cultrix: 21-29, 1996.

CORREIA, F.A. Alguns desafios da bioética. In: PESSINI, Léo \& BARCHIFOTAINE, C. de P. de (Orgs.). Fundamentos da bioética. São Paulo, Paulus, 1996.

CORNU, D. Jornalismo e verdade: para uma ética da informação. Lisboa-Portugal, Instituto Piaget: 383, 1994.

DIZARD JR., W. A nova mídia: a comunicação de massa na era da informação. 2. ed. Rio de Janeiro, Jorge Zahar, 2000.

HABERMAS, J. Teoria de la acción comunicativa II: crítica de la razón funcionalista. Madri, Taurus, 1992

KANT, I. Resposta à pergunta: o que é esclarecimento? In: Textos selecionados. Petrópolis, Vozes, 1985.

KIPPER, D. \& CLOTET, J.: 104. Princípios da beneficência e não-maleficência. In: Costa, S. I. F.; Garrafa, V. \& Oselka, G. (Orgs.) Iniciação à Bioética. Brasília, CFM: $37-51,1998$.

KUCINSKI, B. Jornalismo em crise: uma nova ética para uma nova modernidade. Texto apresentado no V Fórum Nacional de Professores de Jornalismo, Porto Alegre, 2000.

PESSINI, L. \& BARCHIFONTAINE, C. de P. de. Problemas atuais da bioética. São Paulo, Loyola, 1991.

POTTER, Van R. Bioethics: bridge to the future. New Jersey: Prentice-Hall, Englewood Cliffs, 1971.

POTTER, Van R. Global Bioethics. Michigan, Michigan State University Press, 1988.

RAWLS, J. Uma teoria da justiça. São Paulo, Martins Pena, 2000.

RIBEIRO, A. Caso escola base: os abusos da imprensa. São Paulo, Ática, 2001.

ROSSI, C. O que é jornalismo. São Paulo, Brasiliense. Coleção Primeiros Passos, 1980.

SERVA, L. Jornalismo e desinformação. São Paulo, Senac, 2001.

SIQUEIRA, J. E. de. Ética e tecnociência. Londrina, Ed. UEL, 1998.

SIQUEIRA, J. E. de, PROTA, L.; ZANCANARO, L. (Orgs.). Bioética: estudos e reflexões 1. Londrina, Ed. UEL, 2000.

WEBER, M. A ética protestante e o espírito do capitalismo. São Paulo, Pioneira, 1987.

Recebido em 5/4/2005

Aprovado em 25/4/2005 